\title{
Prevention of occupational accidents and diseases in the logistics of goods distribution in city centres: the case of electric trucks
}

\author{
L. Wioland \& V. Govaere \\ Working Life Department, INRS, France
}

\begin{abstract}
"Urban freight distribution" or "urban distribution" can be defined as the art of enabling a city's incoming, outgoing, and internal flows of goods to be organized as well as possible. Currently, one of the biggest constraints is environmental pressure. One of the strategies for satisfying that constraint is "clean delivery", using electric vehicles. This strategy requires logistics to be organised by locating specific logistics facilities (platforms) close to the cities, in particular to cope with the limited ranges of such vehicles. With the aim of preventing occupational accidents and diseases, this manner of organising logistics was analysed. The method used was based on an ergonomics approach to analysing the activities of the platform employees and of the drivers. The results highlight a certain number of difficulties and risks related to those activities and have made it possible to define avenues to be explored for improving working conditions and prevention. The method incorporates the systemic view that urban distribution constitutes the final link in the supply chain. Its activity is therefore seen as being potentially dependent to an extent on the activities of the other links in the supply chain. Thus, in terms of occupational accident and disease prevention, an "act elsewhere" approach has been imagined. This approach is designed to be deployed in a given work situation in order to improve not only that situation but also the work situation that is connected to it.
\end{abstract}

Keywords: prevention, health, safety, urban freight distribution, platform, electric vehicles, supply chain. 


\section{Introduction}

\subsection{Context}

"The supply chain" encompasses all of the resources, means, methods, tools, and techniques involved in bringing goods from supplier to customer as efficiently as possible. The aim is to deliver the right product to the right place and at the right time, while also keeping optimum control over costs and quality. A finished product delivered to the customer goes through the successive stages of purchasing, procurement, production, and distribution. An issue for the supply chain is to optimise and impart smoothness to the logistics chain as a whole and not segment by segment. In some cases, at the end of the chain, the goods are made available in a city centre, and this is known as "urban distribution". It can be defined as the art of organising as well as possible a city's incoming flows of goods ( $82 \%$, for deliveries), outgoing flows of goods $(9 \%)$, and internal flows of goods ( $9 \%$, loaded and delivered within the city). Although the urban transport stage is the link that is the most costly $(20 \%$ of the total cost of the logistics chain in 2009), it seems likely that it will continue to exist. Nearly $80 \%$ of European citizens live in urban areas [1], and demand for home deliveries is growing, as is e-commerce (which has grown by $35 \%$ in 10 years). Urban logistics is part of the economic and social development of city centres [2]. Constraints weigh heavily on this sector, including traffic difficulties, or indeed regulations specific to the city centre (restrictions on delivery times, traffic banned from certain zones, etc.). Currently, one of the most marked constraints is environmental pressure (increase in regulatory requirements on pollutant discharge, noise, etc.). The road haulage sector emits $6.7 \%$ of the total emissions of $\mathrm{CO}_{2}$ in France (key figures from the French Ministry of Transport, 2013). The hauliers have committed to reducing their share in $\mathrm{CO}_{2}$ emissions by modernising their vehicle fleets, reducing fuel consumption, or training their drivers in eco-driving. Other strategies have been imagined in the sector; the aim is not to given an exhaustive presentation of all of the existing, but rather to analyse one of them: namely the development of transport using "clean vehicles", and in particular electric vehicles. That strategy requires distribution logistics to be organised by locating specific logistics facilities, namely platforms, close to the cities, in particular to cope with the limited range of this type of vehicle. These platforms are the places where the goods are delivered, subdivided into smaller batches, and then taken charge of by the drivers who deliver them by electric vehicle to the various customers.

\subsection{Health and safety}

Very often, studies analyse a particular node of the supply chain independently and in isolation from the rest of the supply chain. However, the supply chain is like a network of interconnected enterprises, each one of which is potentially dependent on what happens upstream and/or downstream from its activity. Urban distribution constitutes the segment of the chain that is furthest downstream. Each node is connected via the transport function. The nodes are zones that are "fragile" 
and "under strain" because transloading takes place there, the flow of information is interrupted there, and operators from different trades and enterprises work there together. Studies referring to health and safety aspects generally concern the employees of a node, and often the population in question is made up of the drivers doing long-distance or regional haulage $[3,4]$. Ultimately, studies relating to the activity of urban distribution do not really incorporate the health and safety aspects.

And yet such health and safety aspects appear as a separate issue in their own right for French enterprises, for at least three reasons. One of these reasons is that employers have obligations to achieve results in terms of preventing occupational accidents and diseases (Article L4121-1 of the French Labour Code). Another reason is that, compared with other sectors of activity, the transport and logistics sector would appear to be marked by a high accident and disease rate. In 2012, occupational accidents and diseases in this sector caused 1,700,000 work days to be lost, i.e., on average, 70 work days lost per enterprise. The operators in this sector are mainly exposed to two types of risks:

- Physical risks: risks of road accident, or collision, and of being run over or crushed related to use of motor-driven goods-handling trucks and devices, risks of Musculoskeletal Disorders (MSDs) of the limbs and of the spine that are related to goods-handling and to vibration generated by the vehicle [5].

- Psychosocial risks: risks of stress related to tight time constraints, to quality requirements, and to mental overload (managing contingencies, very full delivery round, etc.) $[6,7]$.

As regards the specificity of driving an electric vehicle, studies have, above all, related to private use of this type of vehicle. In that context, the main question that is raised concerns the impact of the limited range of the vehicle on the driving activity. Since the range of the vehicle is not simple to determine accurately and to anticipate, and since the recharging means are not necessarily accessible rapidly, using an electric vehicle generates worry, uncertainty, and anxiety ("range anxiety") $[8,9]$. This problem is described as being the main obstacle to the development of this mode of transport [10]. Apart from this point, the effects on health and safety of driving and delivering goods by electric vehicles are hardly addressed by any studies.

\subsection{Objectives}

The objective of this study is to define occupational accident and disease prevention principles that are appropriate for interconnected transport and logistics enterprises, i.e. appropriate for the supply chain. For this purpose, the study focuses on one part of the supply chain: urban distribution. This segment is constituted by a platform connected to customers via electric goods transport. The study was conducted in a transport company working for a national agency with whom the customer orders are placed. The orders are then prepared by the logistics branch of the company and then transferred to its transport unit. The goods are then transported every night by truck to the platform close to the urban centre. 
Depending on the period, from 40 to 50 employees work there (management, loading-bay supervisor, and drivers). The goods arrive at about 4 a.m. and are checked, sorted, and split up into delivery rounds. The deliveries are made mainly with fully electric vehicles (with payload capacities of 2 metric tons), and a few are made with hybrid vehicles. Two delivery rounds are scheduled per day for each vehicle and driver. After the first rounds (starting at about 4:30 a.m. and finishing about 8 a.m.), the drivers return to the platform to recharge the batteries of their trucks and to organise the goods they are going to deliver on the second rounds. The company has an Information System (IS) making it possible to track the goods all the way to delivery to the customers. Depending on the tasks to be performed, the IS is in the form of software on a computer, or in the form of a Personal Digital Assistant (PDA) for the drivers.

\section{Method}

The method used was based on an ergonomic approach in a real work situation. It was made up of two parts. The first corresponded to analysis of the activity of the operators on the platform in a normal situation and in a complex situation (peak activity). The links between the platform and the node that was located upstream were taken into account but they were not the subject of an analysis proper. The second part concerned analysis of the delivery activity of the drivers.

To conduct these activity analyses, "paper and pencil" type observation techniques and video recording observations techniques were used. Then interviews were conducted with the management, the employees of the platform, and the drivers. The resulting data is essentially qualitative. Some of that data is supplemented by quantitative data from systematically coding the activities of the operators. The data collection was organised into 4 separate time phases: a phase of pre-observation for 3 days; a campaign of measurements conducted for 5 days in a row (4:30 a.m. to 5 p.m.) on the platform for the normal situation; a campaign of observations for 4 days in row for the peak activity situation; and a campaign of measurements for 3 days in a row (4:30 a.m. to 2 p.m.) for the deliveries part.

\section{Results}

\subsection{Description of the activity of the platform operators in a normal situation}

\subsubsection{The management}

The platform management players are constituted by the platform manager and his assistant. The observations and interviews made it possible to identify 3 main functions for them. They constitute the "interface" between the platform and the national agency: they receive the assignments. They manage and then feedback all types of information, including the information relating to the deliveries made and to the administrative aspects. They update the database of the information system to enable the national agency to continue the goods management process (e.g. to launch the invoicing stage). A certain number of procedures to be complied with 
are defined by the national agency (e.g. for tracking the goods), but the management enjoy relative autonomy, in particular as regards defining the means to be implemented. They play the part of "conductors": they distribute the assignments to be done, and coordinate all of the activities of the operators to attain the objectives. They also manage all of the employees of the platform from a human resources (HR) point of view "locally" (the major decisions are taken by the HR Manager of the national agency). They make sure the assignments are performed properly: they handle all contingencies (e.g. they find replacements for unscheduled absentees, regardless of the job in question) and incidents of all types (equipment or administrative). They manage the vehicles, and maintenance of them, and they are watchful to ensure that the vehicles are all recharged properly for the next day. They make all the preparations necessary so that the next day's deliveries go as well as possible (preparing the parcels, organising the storage in rows). They enjoy autonomy in deciding which means to use for performing this assignment.

\subsubsection{The loading-bay supervisor}

A loading-bay supervisor assists the management team. Coding his activity made it possible to have a representation of the distribution of his various tasks. Eighteen and a half hours of activity were coded for this operator over 3 days of observations. The results show that most of his activity is "mental" (55\% of his time at work). That $55 \%$ covers the following cognitive activities:

- The activity of planning: $7 \%$ for the first delivery rounds and $44 \%$ for the second delivery rounds. This difference can be explained by the fact that the schedules of the first rounds are identical from one week to another, and they are drawn up by the national agency and then given to the loading-bay supervisor who adapts them to cope with contingencies (e.g. absences). The schedules of the second rounds are drawn up entirely by the loading-bay supervisor and their contents can be changed up to the last minute. The loading-bay supervisor then distributes the schedules to the drivers and gives them specific instructions when there are difficulties with certain customers (e.g. goods are missing).

- The activity of checking: $29 \%$ for checking the information from the PDA with the various databases of the information system, and for checking that the goods delivered are the goods expected (comparing the delivery documents with the numbers of the unloaded parcels, etc.).

- The administrative activity: $20 \%$ for dealing with emails from the national agency, for updating the databases, for drawing up working documents for planning, tracking, and monitoring, etc.).

The activity of goods handling represents only $10 \%$ of his work time. It mainly concerns storing the goods in rows according to final destination, and more occasionally helping drivers to load parcels into their trucks. The other significant activity is managing the PDAs (22\%). This activity consists in loading into the PDAs the appropriate information for the various rounds, and in distributing them to the appropriate drivers (list of goods and customers). Once the drivers have scanned the goods loaded into their trucks, the loading-bay supervisor then 
empties the PDAs and checks that all of the goods have been properly scanned (comparing two computer files). If everything has been properly scanned, the driver goes on the delivery round. Otherwise the driver must look for the parcels in question and scan them. $5 \%$ of the activity of the loading-bay supervisor relates to managing the electric vehicles and $8 \%$ to performing related tasks (managing the waste at the loading bay, etc.)

\subsection{Description of the activity of the drivers in a normal situation}

About thirty drivers deliver the goods to the end customers in the city centre. The analysis of the activity of the drivers was conducted on 6 drivers doing different rounds. In all, 45 hours of coding and observations were conducted. The results show that, for more than half of the observation time (54\%), the activity of the drivers consisted in city driving. They made numerous information acquisitions or checks that were coded. It transpired that $46 \%$ of them related to routes given by the satellite navigation system, $40 \%$ concerned the state of charge of the battery, and $14 \%$ administrative documents. The activity of the drivers that was ranked second in terms of time spent was delivery (15\%). The delivery time corresponds to the time that elapses between the truck stopping for unloading the goods and handing them over, and the truck driving off again. The driver can also have to wait at the delivery points of the customers before being able to deliver the goods ( $10 \%$ of his time). It is an indicator that the activity of the driver is not continuous and that his activity is dependent on the opening hours of the customers. Time spent on the platform represents $8 \%$ of the total time of the activity of the drivers. They remain there for from 20 minutes to 1 hour, depending on the difficulties or incidents encountered. On the platform, their main activity is devoted to preparing the load (74\% of their time). Such preparation includes goods-handling, reorganising the parcels on pallets for optimising the deliveries (putting the parcels in order of delivery, ensuring that the parcels are stable on the pallets, wrapping film around them, etc.). As regards preparing the goods to be loaded into the trucks, each driver organises the work as he wishes, and there are no formalised rules. The drivers enjoy autonomy in defining the order of their various delivery points. Administrative tasks are ranked second in terms of time spent on them ( $20 \%$ of the drivers' time at the loading bay). They consist in managing the documents related to deliveries and also the activities related to the traceability of the goods (use of the PDA). Managing their trucks (plugging in the battery, checking that everything is working) accounts for $6 \%$ of their activity time at the loading bay). Then come goods handling and the administrative activity ( $4 \%$ each) and break time (5\%). In terms of communication, the drivers spent most of their communicating time talking to customers ( $45 \%$ of the discussion time), the loading-bay supervisor and the management $(22 \%)$, and also with other drivers (24\%). From a qualitative point of view, exchanges of information between drivers essentially concern the way they prepare their loads, any difficulties related to traffic or to the delivery proper, optimum routes, etc. These exchanges reflect that they work together and give mutual assistance to one another. 


\subsection{Difficulties and risks}

The observations and interviews made it possible to identify 5 main classes of difficulty:

- Difficulties related to interdependence: the activity of the platform is, to a large extent, dependent on the activity of the national agency. It was observed that certain effects related to certain difficulties, specific to the national agency, are passed on to the activities of the platform operators and of the drivers. For example, delays in deliveries of goods coming from the national agency were observed. Such delays generate "uncertainty" for all of the operators who are then in a waiting position, and "tension" because they do not know whether or not they are going to be able to manage and deliver the goods within the allotted times. The later a truck is, the more difficult it is for the operators, who are aware that some customers can refuse to take delivery of the goods or can ask for financial compensation. To mitigate such delays, the loading-bay supervisor regularly asks the national agency for information so as to remove the uncertainties and so as to anticipate the organisational changes to be implemented. When the truck arrives, the operators reorganise themselves; those who are available, regardless of their function, help to unload the truck and to manage the goods. This reorganisation reduces the time available for the drivers for managing and preparing the goods and for loading them.

- Difficulties related to the interactions between national agency operators and platform operators exist: lack of communication and of coordination between the two sites were observed. For example, the national agency requires a new administrative task to be performed (inputting data into new dashboard-type progress charts) but neither the management nor the loading-bay supervisor are informed of the reasons and of the procedures to follow. This new task is felt to be an additional task that is not justified, and that is complex to perform. The interviews about this event made it possible to provide information on what the platform operators felt. They reported that they had the impression the national agency operators did not really know and were not interested in their actual activity and their constraints. The interviewed operators spoke of "lack of recognition". Such lack of communication and of coordination, related mainly to organisational factors, degrades the social relations and weakens the intersite team spirit. Similarly, it was observed that certain human resources management decisions taken by the platform manager are not necessarily supported by the national agency. Therefore, it is frequent for certain drivers to bypass the platform manager and go directly to the human resources manager of the national agency. This example illustrates a lack of clarity in how the tasks, roles, and responsibilities of the various managers on the two sites are shared out.

- Difficulties related to material resources were observed: management of the batteries is crucial and recharging incidents occur. Some mornings 
trucks were seen whose batteries had not been fully recharged for various reasons (equipment problems, not properly plugged in by the drivers, etc.). This type of event constrains the driver to look for another truck. When trucks are already in short supply for reasons of high activity or of maintenance, the driver has no other choice than to use a truck that is not fully charged (forcing him to perform his delivery task while being in fear of breaking down, and thus with a higher mental workload, e.g. checking the state of charge of the battery more often) or else to ask for changes to be made to his round (constraining him to rethink the way he intended to do it). Problems of reliability of display of the battery state indicator were also observed. For example, certain trucks still display 30\% charge before the battery suddenly discharges completely. This is a known phenomenon, and it is thus taken into consideration by the drivers in choosing their vehicles. These events also generate situations of uncertainty during the driving activity, and a lack of trust in the vehicle.

- Difficulties related to the computer tools were observed: bar code incomplete or PDA not working, requiring a return to the old paper method. Inconsistencies were observed between the computerised administrative information and the information on the goods. These inconsistencies require drivers to make additional checks and to be vigilant, and also to perform extra handling operations, interfering with other work, for counting and looking for the parcels.

- Difficulties related to the delivery activity were observed: traffic and site access difficulties (absence of dedicated delivery areas, deliveries in complex zones such as shopping centres, shop cellars, etc.), and constraints related to the delivery times having to be during shop opening hours. The absence of goods-handling equipment appropriate for city deliveries (in particular for mitigating the problems of coping with kerbs and street furniture) and the heterogeneity of the goods in terms both of volume and of weight makes them complex to handle when unloading them at the customer's premises. Constraints related to the interactions with the customers were identified (unpleasant reception from the customer, refusal to take the goods, distribution of the work between driver and customer sometimes "vague", etc.). All of these difficulties can make the driver's task complex, in particular when he has to cope with more than one of them at the same time. In order to regulate and accomplish their assignments within the allotted time, the drivers develop strategies. They plan various scenarios on the basis of hypothesis on the way in which the goods can be taken charge of, they include their experience of the encountered situation, and they build networks of "good relations" for customers to whom they deliver regularly, enabling them to deliver more easily and quickly.

For all of the operators, uncertainty, tensions, lack of recognition, lack of trust in certain equipment, deterioration in social relations and weakening of inter-site team spirit, work and attention overload, time pressure, waiting, and confusion of roles constitute psychosocial risk factors. However, these risks are partly offset by 
the operators having a relatively large amount of autonomy and by the existence of room for manoeuvre or leeway. Complex extra goods-handling operations that interfere with other work mainly constitute MSD and low back pain risks. Traffic, site access, and vehicle manoeuvring difficulties, as well as the multiple information acquisitions or checks, and organisational and re-organisational operations give rise to accident risks.

\subsection{Activity of the operators in a complex situation}

The complex situation observed corresponded to the consequences of the arrival of a new customer to be managed in addition to the usual activity. The volume of goods to be dealt with doubled. The immediate consequence was considerable extra load for the platform, reinforcing the risks related to moving around the platform (collisions, being crushed or run over, etc.) and the risks of error (parcels lost or mixed up, for example). In spite of the presence of temporary staff for helping with the operations, an intensification of their mental and physical activities was noted. The operators, including all functions, had to make additional and complex checks (new, unknown goods that were very heterogeneous), and had to be more vigilant to avoid or make up for errors. Goods-handling operations (looking for parcels, sorting, goods to be wrapped in film, etc.) were more numerous, and some of them interfered with other work. The difficulties identified in normal situations were to be found to a more sustained extent. For example, the lack of communication with the national agency meant that it was not possible to anticipate certain difficulties. The operators work and organise themselves reactively as the day and the events go by, with a great deal of uncertainty. The material resources problems are accentuated giving rise to competition between the drivers and thus weakening the team spirit. At delivery level, the same difficulties appear, with less room for manoeuvre to absorb them, in particular due to the increase in the number of customers to deliver to. Certain new difficulties come to be added: new customers, specific new constraints in terms of access and hours that are difficult to anticipate. For example, the new customer has the goods delivered to nursery and infant schools, which requires complex and constraining paths through the schools (going back and forth on stairs while carrying voluminous and heavy parcels, going through offices, being in contact with the children, etc.). Since the new customer is not already input into the IS database, the goods are processed manually, resulting in longer times for each of the processing steps, and a major risk of errors. All of the employees have to absorb these constraints, and this has a physical and mental cost.

\subsection{Avenues for improvements}

The difficulties identified can be categorised into 3 classes. The difficulties specific to each level (national agency, platform, and deliveries), the difficulties relating to interaction between these levels, and the difficulties related to them being interdependent. These three categories of difficulty were discussed with the company to define avenues for thought on improving working conditions and prevention. 
The difficulties specific to each of the levels (national agency, platform, and delivery) mainly concern the risks related to moving around the platform, to the goods-handling activity, and to the material resources. The solutions discussed with the company concern putting in place clear organisation of the flows of goods and of the circulation paths and gangways on the platform, and putting in place organisation of storage so as to facilitate goods handling. These avenues for thought are particularly crucial for situations during which activities peak. It was agreed that the drivers should feed back to the management of the platform or to the loading-bay supervisor any difficulties and malfunctioning encountered with the customers. The management should then talk to the customers and find compromises for improving the situation. More specifically, concerning the material resources, namely management of the electric truck, the phenomenon of "range anxiety" described above is found again. This phenomenon constitutes a mental constraint for drivers and leads them to put in place strategies for mitigating it (anticipating returning to the platform to the detriment of the deliveries in order to avoid breaking down, for example). Currently, in terms of prevention, one of the best ways of preventing this phenomenon of "range anxiety" remains the way in which the delivery rounds are planned. In goods transport in general, delivery round planning is a decisive factor, but for deliveries by electric vehicle, it becomes essential. The difficulty lies in the fact that this technology is recent and that it is complex to find solutions, including with the manufacturers. Even though this technology is tried and tested, and has, in particular, made it possible to satisfy environmental constraints and to offer certain advantages for urban delivery, its diffusion is mainly hindered by issues of cost, maintenance, and technological difficulties related to the range or autonomy of the batteries $[11,12]$.

The difficulties relating to interactions between the national agency, the platform, and deliveries: mainly concern the difficulties related to communication and coordination. The main avenue for finding solutions to these problems concerns improving organisation so as to make inter-site synergy possible (beyond mere juxtaposition). Such synergy would mainly require needs to be better explained and better listened to, roles and responsibilities to be defined clearly, and information to be passed around and shared. This action would make it possible to reduce uncertainties, and to anticipate and to organise to cope with urgent situations.

The difficulties related to the interdependence of the levels (national agency, platform, and deliveries): they illustrate the phenomenon of propagation [13]. This is a phenomenon whereby factors of degradation of one work situation are passed on to another, connected work situation. Thus, the operators at the national agency have been included in developing avenues for finding solutions to this category of difficulties. This approach involved making a short diagnostic analysis of their situation to identify their own difficulties and to define appropriate levers for action. The trucks leaving late to go to the platform was pinpointed as being due to organisational difficulties that have been discussed and thought about with them to find an improvement. We do not need to describe the contents of that diagnostic analysis, but we should retain the principle of it. 


\section{Discussion and conclusion}

The three categories of difficulties identified, namely the ones specific to each of the levels, the ones relating to the interactions between those levels, and the ones related to their interdependence, lead to avenues for recommendations that come under different approaches:

- The first one comes under an approach usually deployed in ergonomics, where detection of a problematic work situation leads to an analysis of that situation, and then to proposed prevention solutions appropriate to it.

- The other two require understanding of how these various levels interact and have impacts on one another, and therefore also need to be analysed at least to a minimum extent. The intra-site interactions between operators on the same site are often integrated. However, the inter-department interactions are integrated to a lesser extent, and the inter-site ones are almost never integrated. The difficulty lies in that fact that implementing a solution that is targeted on a single one of these work situations does not prevent the propagation of the degradation factors to the connected situations from continuing. For example, in this study, it would have been vain to implement only solutions targeted on the platform in order to solve the difficulties related to its interdependence with the national agency. Similarly, addressing only the deliveries activity of the drivers without addressing the activities of the platform operators would have given a diagnostic analysis that was only partial, and therefore avenues for solutions that were incomplete.

To conclude, regardless of the supply chain segment in question, addressing the health and safety of the operators as comprehensively as possible cannot be done solely from a single level or from a single work situation; It is crucial to take into account what happens upstream and downstream. Analyses of the situation should be conducted with particular attention being given to the interactions between the operators of the other departments of the company or of external companies so as to distinguish between the constraints/resources specific to the work situation and those coming from other situations. By distinguishing the "origins" of the constraints/resources, the level on which action should be taken is identified more appropriately (on the situation itself? On a connected situation?). In terms of approach for preventing occupational accidents and diseases, this approach, called "act elsewhere" $[14,15]$, is intended to be deployed in a work situation so as to improve not only that work situation but also the work situations that are connected to it. This prevention approach appears to a promising one for a sector such as the transport and logistics sector, where enterprises are interconnected, and in which health and safety problems are very marked. This approach would be supplementary to the actions conventionally implemented, but it remains to be developed in more depth, in particular regarding the methodological and deployment aspects (how can this approach be lightened in order to make it more accessible to occupational safety and health specialists, for example). 


\section{References}

[1] Cherett, T., Allen, J., McLeod, F., Maynard, S., Hickford, A., Browne, M. Understanding urban freight activity - key issues for freight planning, Journal of Transport Geography (24) pp. 22-32, 2012.

[2] Corso, M. Des solutions alternatives au pétrole et durables s'imposent, l'officiel des transporteurs, $\mathrm{N}^{\circ} 2814$ janvier, 2016.

[3] Apostolopoulos, Y., Shattell, M.M., Soenmez, S., Strack, R., Haldeman, L., Jones, V. Active Living in the Trucking Sector: Environmental Barriers and Health Promotion Strategies. Journal of Physical Activity \& Health, Vol. 9, pp. 259-269, 2012.

[4] Hamelin, P. La durée de travail des conducteurs professionnels comme enjeu de la flexibilité et da la compétitivité des transports routiers de marchandises et de voyageurs, BTS newsletter $\mathrm{N}^{\circ}$ 15-16, pp. 42-51, 2001.

[5] Thierry S., Chouanière D., Aubry C. Conduite et santé, une revue de la littérature. Documents pour le Médecin du Travail, INRS, No 113, pp. 4563, 2008.

[6] Bourdarias, F. Espace de travail, espaces familiaux: La transformation des conditions de la pratique professionnelle des conducteurs routiers, Predit 1996-2000, Ministère des Transports et DRAST, p. 193, 2000.

[7] Makishita, H., Matsunaga, K. Differences of drivers' reaction times according to age and mental workload. Accident Analysis and Prevention, Vol. 40, pp. 567-575, 2008.

[8] Franke T., Neumann I., Buhler F., Cocron P., Krems J.F. Experiencing range in an electric vehicle: understanding psychological barriers, Applied Psychology 61(3) pp. 368-391, 2012.

[9] Nguyen C., Cahour B. Véhicule électrique et gestion de son autonomie: une approche prospective ancrée dans l'expérience vécue, Revue Le Travail Humain, Vol. 77(1) pp. 63-89, 2014.

[10] Krupa J.S., Rizzo D.M, Eppstein M.J., Lanute B. D, Gaalema D.E., Lakkaraju K., Warrender C.E. Analysis of a consumer survey on plug-in hybrid electric vehicles Transport Research. Part A: Policy Pract., Vol. 64, pp. 14-31, 2014.

[11] Lebeau P., De Cauwer C., Van Mierlo J., Macharis C., Verbeke W., T. Coosemans, Conventional, Hybrid, or electric vehicles: which technology for an urban distribution centre, The Scientific World Journal, pp. 1-11, 2015.

[12] Feng W., Figliozzi M.A. Conventional vs electric commercial vehicle fleets: a case study of economic and technological factors affecting the competitiveness of electric commercial vehicles in the USA, ProcediaSocial and Behavioral Sciences, Vol. 39, pp. 702-711, 2012.

[13] Govaere, V. Changements de l'activité de travail liés aux NTIC: analyse ergonomique du phénomène de propagation et retombées en prévention. Références en Santé au Travail, TF 206, N 133, pp. 43-58, 2013. 
[14] Govaere V., Wioland L. Symposium: "Distribution en logistique quel équilibre entre santé et performance?" 50ème Congrès de la SELF, p. 12, 2015.

[15] Wioland L. Ergonomic Analyses in the Transport and Logistics Sector. Reflection on developing a new Prevention Approach: "Act Elsewhere", Accident Analysis and Prevention, pp. 213-220, 2013. 